\title{
1,3-Butadiene-Induced Mitochondrial Dysfunction is Correlated with Mitochondrial CYP2E1 Activity in Collaborative Cross Mice
}

Jessica H. Hartman, ${ }^{1}$ Grover P. Miller, ${ }^{1}$ Andres A. Caro, ${ }^{2}$ Stephanie D. Byrum, ${ }^{1}$ Lisa M. Orr, ${ }^{1}$

Samuel G. Mackintosh, ${ }^{1}$ Alan J. Tackett, ${ }^{1}$ Lee Ann MacMillan-Crow, ${ }^{3}$ Lance M. Hallberg, ${ }^{4,5}$ Bill T. Ameredes, ${ }^{5,6}$ and Gunnar Boysen ${ }^{7,8}$ 


\begin{abstract}
Cytochrome P450 2E1 (CYP2E1) metabolizes low molecular weight hydrophobic compounds, including 1,3-butadiene, which is converted by CYP2E1 to electrophilic epoxide metabolites that covalently modify cellular proteins and DNA. Previous CYP2E1 studies have mainly focused on the enzyme localized in the endoplasmic reticulum (erCYP2E1); however, active CYP2E1 also localizes in mitochondria (mtCYP2E1) and the distribution of CYP2E1 between organelles can influence an individual's response to exposure. Relatively few studies have focused on the contribution of mtCYP2E1 to activation of chemical toxicants. We hypothesized that CYP2E1 bioactivation of butadiene within mitochondria adversely affects mitochondrial respiratory complexes I-IV. A population of Collaborative Cross mice were exposed to air (control) or $200 \mathrm{ppm}$ butadiene. Subcellular fractions (mitochondria, DNA, and microsomes) were collected from frozen livers and CYP2E1 activity was measured in microsomes and mitochondria. Individual activities of mitochondrial respiratory complexes I-IV were measured using in vitro assays with purified mitochondrial fractions. In air- and butadieneexposed mouse samples, mtDNA copy numbers were assessed by RT-PCR, and mtDNA integrity was assessed through a PCR-based assay. No significant change in mtDNA copy number or integrity were observed; however, there was a decrease in overall activity of mitochondrial respiratory complexes I, II, and IV after butadiene exposure. Additionally, higher mtCYP2E1 (but not erCYP2E1) activity was correlated with decreased mitochondrial respiratory complex activity (in complexes I-IV) in the butadiene-exposed (not control) animals. Together, these results represent the first in vivo link between mitochondrial CYP2E1 activity and mitochondrial toxicity.
\end{abstract}




\section{Introduction}

Toxicities arising from exposures to drugs, pollutants, and food additives often depend on metabolic processing by cytochromes P450 (CYP for specific enzymes). A relatively low substrate specificity for CYP2E1 yields a versatile enzyme for metabolically eliminating a wide array of mostly small molecules (molecular weight <100), yet paradoxically, increases the probability of creating metabolites that are toxic (Lieber 1997; Miller 2008). Moreover, reactive oxygen species (ROS) are often a by-product of inefficient CYP2E1 metabolism and produce various reactive molecules through oxidative stress and lipid peroxidation. Many of the reactive molecules derived from CYP2E1 activity are known to form DNA and protein adducts that are in contrast to the beneficial role of CYP2E1 in eliminating toxicants. Knowledge of the balance between toxicity and detoxification requires a comprehensive understanding of factors modulating the contributions and consequences of CYP2E1 activity to the metabolism of its substrates.

Like other P450s, CYP2E1 was originally discovered in a microsomal liver fraction containing essentially the endoplasmic reticulum (erCYP2E1)(Koop et al. 1982). Since then, microsomal fractions or whole cell preparations have served as tools for studies assessing the impact of P450 activity on biological processes and thus, the foundations for toxicological mechanisms. Nevertheless, CYP2E1 is among a few of the microsomal P450s capable of expression in an active form within mitochondria(Avadhani et al. 2011), yet mitochondrial CYP2E1 (mtCYP2E1) has only recently begun to be characterized for its metabolic properties(Hartman et al. 2015; Robin et al. 2002; Robin et al. 2001) and its impact on normal cellular and mitochondrial functions (Abdelmegeed et al. 2015; Bai and Cederbaum 2006; Bansal et al. 2013; Bansal et al. 2010). The sole expression of CYP2E1 in mitochondria of 
transfected HepG2 or COS-7 cells leads to higher levels of ROS and oxidative stress, mitochondrial dysfunction, and cytotoxicity, especially in the presence of acetaminophen or ethanol(Robin et al. 2005; Sangar et al. 2010). These findings with cellular models provide strong in vitro evidence for the ability of mtCYP2E1 metabolism to alter normal cellular function, yet in vivo evidence is still lacking such that its relevance in toxicological mechanisms remains unclear.

1,3-Butadiene is an excellent model substrate for assessing impact of CYP2E1 localization on its in vivo activation into reactive metabolites. Butadiene is a common industrial chemical and cigarette smoke constituent that has been classified as a human carcinogen(Himmelstein et al. 1997; Kirman et al. 2010). The toxicity of butadiene arises from the well-characterized metabolism of butadiene by CYP2E1 to reactive epoxide metabolites (3,4-epoxy-1-butene, 1,2:3,4-diepoxybutane, 1,2-butenediol, and 1,2-epoxybutane-3,4-diol), shown in Figure 1. These epoxide metabolites have been demonstrated to form covalent adducts with glutathione, DNA, and proteins in vitro and in vivo (Boysen et al. 2007a; Cho and Guengerich 2012; Georgieva et al. 2010; Koivisto et al. 1999; Koivisto et al. 1997). While the importance of activation/metabolism by microsomal CYP2E1 has been established, less is known about the contribution of mitochondrial CPY2E1.

In this study, we used a genetically diverse Collaborative Cross mouse population model to demonstrate ex vivo the relationship between mtCYP2E1 activity and mitochondrial dysfunction after butadiene exposure. The Collaborative Cross is a large panel of new inbred mouse strains currently being developed through a global community effort (Churchill et al. 2004). The Collaborative Cross strains are derived from an eight way cross using a set of founder strains that include three wild-derived strains. It is designed to represent a genetically heterogeneous 
population with an even distribution of allelic variation, which closely resembles the genetic diversity found in human populations (Chesler et al. 2008; Churchill et al. 2004; Threadgill et al. 2002).

Mice from sixty individual Collaborative Cross strains were exposed to either air (control) or $200 \mathrm{ppm}$ butadiene for 10 days, after which the livers were harvested and flash-frozen for later analysis. Mice used for this investigation are part of a larger study to determine variability in metabolic activation of 1,3-butadiene. Previous toxicity and carcinogenicity studies utilized almost exclusively B6C3F1 mice and exposures from 0.01 to $1250 \mathrm{ppm}$ for 10 or 20 days. Our group is extending the toxicity studies to a population of genetically diverse mice to determine if the $\mathrm{B} 6 \mathrm{C} 3 \mathrm{~F} 1$ mouse strain is of susceptible or resident phenotype compared to a genetically diverse mouse population. The $200 \mathrm{ppm}$ 1,3-butadiene exposures are at the higher end of exposures than can be expected in human situations, but previous work has shown that metabolism is linear up to $200 \mathrm{ppm}$, making this exposure concentration suitable to investigate the contribution of mtCYP2E1 on 1,3-butadiene metabolism.

Subcellular fractions were isolated from liver tissue (total DNA, microsomes, and mitochondria) and CYP2E1 activity was measured in microsomes and mitochondria. The consequences of CYP2E1 activity on mitochondrial integrity and function were assessed through exploratory studies measuring mitochondrial DNA (mtDNA) copy number, mtDNA integrity, and mitochondrial respiratory complex in vitro activities. Moreover, we assessed correlations between respiratory complex activities and with either erCYP2E1 or mtCYP2E1 activities. Lastly, we investigated possible post-translational modification of mitochondrial respiratory proteins to explain changes in activities by CYP2E1-derived butadiene reactive metabolites using a proteomic LC-MS/MS approach. 


\section{Experimental Procedures}

\subsection{Chemicals}

All chemicals were HPLC grade or higher. The following were purchased from Sigma Aldrich, St. Louis, MO: 4-nitrophenol, 4-nitrocatchol, 4-nitroanisole, perchloric acid, bovine serum albumin, n-dodecyl $\beta$-D-maltoside, adenosine 5'-triphosphate (ATP) disodium salt, EDTA, and 2,6-dichloroindophenol. Rotenone, decylubiquinone, and antimycin-A were purchased from Santa Cruz Biotechnology, Dallas, TX. The protease/phosphatase inhibitor cocktail was prepared in-house using the Roche c0mplete ${ }^{\circledR}$ mini EDTA-free tablets from Life Technologies and a phosphatase inhibitor cocktail containing sodium fluoride, sodium orthovanadate, and sodium pyrophosphate. HPLC grade methanol, sucrose, mannitol, succinate, and reduced $\beta$-nicotinamide adenine dinucleotide (NADH) were purchased from Fisher Scientific, Wilmington, MA. DNA isolation was performed using the DNeasy Blood and Tissue Kit from Qiagen (Frederick, MD). RT-PCR experiments were performed using the QuantiTect SYBR Green RT-PCR Kit from Qiagen (Frederick, MD).

\subsection{Animal exposures}

Mice (120 mice, two from each of sixty strains) were obtained from the Systems Genetics Core Facility at the University of North Carolina (Welsh et al. 2012). Previous to their relocation to UNC, CC lines were generated and bred at Tel Aviv University in Israel(Iraqi et al. 2008), Geniad in Australia(Morahan et al. 2008) and Oak Ridge National Laboratory in the US(Chesler et al. 2008). Collaborative Cross mice were divided into two exposure groups, each containing one female mouse from each strain ( $n=60$ for each group) with an average age of 6.6 
\pm 0.77 weeks at experiment initiation. One group was exposed to air (control), and the other group was exposed to $200 \mathrm{ppm}$ inhaled butadiene. After ten days of constant exposure, the animals were euthanized by carbon dioxide asphyxiation. . The liver was harvested and flashfrozen for future analysis. The Institutional Animal Care and Use Committee of the University of Texas Medical Branch Galveston Texas (Protocol number 0808053B) approved all experiments. All experiments were carried out in accordance with established guiding principles for animal research.

\subsection{MtDNA copy number and integrity measurements}

The copy number and integrity of mitochondrial DNA was assessed using purified total DNA from frozen liver tissue. Total DNA was isolated using the Qiagen DNeasy Blood and Tissue kit according to the manufacturer's instructions. The relative number of mtDNA copies in air- and butadiene-exposed mice was determined using RT-PCR amplification of a mitochondrial gene (Cox-1, forward primer 5'-GCCCCAGATATAGCATTCCC-3'; reverse primer 5'GTTCATCCTGTTCCTGCTCC-3') and normalizing it to amplification of a nuclear gene ( $\beta$ actin, forward primer 5'-TGTTCCCTTCCACAGGGTGT-3'; reverse primer 5'-

TCCCAGTTGGTAACAATGCCA-3')(Hance et al. 2005). The integrity of the mtDNA was determined using conventional PCR amplification of a long (10kbp) segment of mtDNA (primers: mtDNA position 3278 5'-GCC AGC CTG ACC CAT AGC CAT AAT AT-3', sense; mtDNA position 13337 5'-GAG AGA TTT TAT GGG TGT AAT GCG G-3, antisense) and normalizing it to amplification of a well-conserved short (117bp) segment of mtDNA (primers: mtDNA position 13597 5'-CCC AGC TAC TAC CAT CAT TCA AGT-3', sense; mtDNA position 136885'-GAT GGT TTG GGA GAT TGG TTG ATG T-3', antisense)(Furda et al. 2012). 


\subsection{Subcellular fractionation}

The liver tissue was homogenized and subcellular fractions were obtained using established and validated methods (Fleischer and Kervina 1974; Gregg et al. 2009) as previously described (Hartman et al. 2015), with some minor modifications. In a typical preparation, $0.1 \mathrm{~g}$ tissue was homogenized in $0.2 \mathrm{~mL}$ homogenization buffer (2.5 mM HEPES, pH 7.4, $220 \mathrm{mM}$ mannitol, 70 $\mathrm{mM}$ sucrose, 2 mM EDTA) using ten smooth, twisting strokes with a $1 \mathrm{~mL}$ Tenbroeck tissue grinder. This isotonic homogenization buffer composition promotes more efficient isolation of mitochondria (data not shown). The homogenate was centrifuged at $4^{\circ} \mathrm{C}, 600 \mathrm{x} g$ for $10 \mathrm{~min}$ to pellet nuclei and unlysed cells. The resulting supernatant was centrifuged a second time at $4^{\circ} \mathrm{C}$, $9000 \mathrm{x} g$ for 20 min to pellet small organelles including mitochondria. The supernatant (S9) was then centrifuged at $4^{\circ} \mathrm{C}, 100,000 \mathrm{x} g$ for $60 \mathrm{~min}$ to isolate the microsomal fraction containing the endoplasmic reticulum. The resulting pellet was resuspended in homogenization buffer with a 1 $\mathrm{mL}$ Tenbroeck tissue grinder using seven smooth, twisting strokes. The resulting homogenate was centrifuged at $4^{\circ} \mathrm{C}, 100,000 \mathrm{x} g$ for $60 \mathrm{~min}$. The supernatant was discarded and the washed microsomal pellet was resuspended in $0.05 \mathrm{~mL} 250 \mathrm{mM}$ sucrose with a $0.1 \mathrm{~mL}$ Tenbroeck tissue grinder. Isolated and purified microsomal fractions were flash frozen and stored at $-80^{\circ} \mathrm{C}$.

\subsection{Purification of mitochondria}

Mitochondria were isolated from other organelles by centrifugation against a sucrose gradient(Meisinger et al. 2000). We have previously demonstrated isolation of a highly enriched purified mitochondrial fraction using this method in frozen liver tissue (Hartman et al. 2015). The crude mitochondrial pellet from initial fractionation steps was washed by resuspending the pellet in $1 \mathrm{~mL}$ SEM buffer (250 mM sucrose, $1 \mathrm{mM}$ EDTA, $10 \mathrm{mM}$ MOPS/KOH, pH 7.2) and 
centrifuging at $4^{\circ} \mathrm{C}, 12,000 \times \mathrm{g}$ for $15 \mathrm{~min}$. The supernatant was discarded and mitochondrial pellet resuspended in $3 \mathrm{~mL}$ SEM buffer. This suspension was layered on top of a discontinuous sucrose gradient consisting of $1.5 \mathrm{~mL}$ 60\% (w/v) sucrose in EM Buffer (1 mM EDTA, $10 \mathrm{mM}$ MOPS/KOH, pH 7.2), $4 \mathrm{~mL} 32 \%(w / v)$ sucrose in EM Buffer, $1.5 \mathrm{~mL} 23 \%(\mathrm{w} / \mathrm{v})$ sucrose in EM Buffer, and $1.5 \mathrm{~mL}$ 15\% (w/v) sucrose in EM Buffer layered respectively in a Beckman SW28 centrifuge tube. Gradient was centrifuged in a Beckman SW28.1 swinging bucket rotor at $4^{\circ} \mathrm{C}$, $28,000 \mathrm{rpm}(140,000 \mathrm{x} g)$ for $60 \mathrm{~min}$. Mitochondrial pellet was a band superficial to the $60 \%$ sucrose layer, which was removed and subsequently diluted in $12 \mathrm{~mL}$ SEM Buffer. The resulting suspension was centrifuged at $4^{\circ} \mathrm{C}, 23,000 \mathrm{rpm}(95,000 \mathrm{x} \mathrm{g})$ for $30 \mathrm{~min}$ in a SW28.1 swinging bucket rotor. The pelleted mitochondria were then resuspended in $0.05 \mathrm{~mL}$ SEM buffer with a $0.1 \mathrm{~mL}$ Tenbroeck tissue grinder. Isolated and purified mitochondrial fractions were flash frozen and stored at $-80^{\circ} \mathrm{C}$.

\subsection{4-Nitrophenol kinetic assay}

We have previously demonstrated that mitochondria and microsomes isolated from frozen rodent liver exhibit organelle-specific CYP2E1 activity(Hartman et al. 2015). To measure CYP2E1 activity in this study, we examined steady-state 4-nitrophenol hydroxylation at the 3position to yield 4-nitrocatechol as previously described(Hartman et al. 2015). For each reaction using microsomal fractions, $0.1 \mathrm{mg} / \mathrm{mL}$ protein was incubated with $50 \mu \mathrm{M}$ 4-nitrophenol in 50 $\mathrm{mM}$ potassium phosphate $\mathrm{pH} 7.4$ at $37^{\circ} \mathrm{C}$. Reactions were initiated with $1 \mathrm{mM}$ NADPH, and after $15 \mathrm{~min}$ of incubation, the reactions were quenched with an equal volume of a solution containing $0.4 \mathrm{~N}$ perchloric acid and $25 \mathrm{mM}$ 4-nitroanisole (internal standard). The quenched reaction was centrifuged to remove precipitated proteins and the resulting supernatant analyzed by HPLC with absorbance detection at $360 \mathrm{~nm}$ to quantitate product. Final 4-nitrocatechol 
concentrations were determined using calibration curves with authentic standards. Under these conditions, product formation was linear with respect to time and protein concentration (data not shown). Similar experiments were carried out for mitochondrial reactions at $0.25 \mathrm{mg} / \mathrm{mL}$ mitochondrial protein.

\subsection{NADH:ubiquinone reductase (Complex I) activity assay}

We determined Complex I activities as the rotenone-sensitive ubiquinone reductase activity in the purified mouse liver mitochondrial samples by measuring ultimately the reduction of the artificial electron acceptor dichloroindophenol (DCIP). For reactions, mitochondria $(5 \mu \mathrm{g} / \mathrm{mL}$ protein) were incubated with $3.5 \mathrm{mg} / \mathrm{mL}$ bovine serum albumin, $60 \mu \mathrm{M}$ DCIP, $70 \mu \mathrm{M}$ decylubiquinone, and $1 \mu \mathrm{M}$ antimycin-A (Complex III inhibitor) in $25 \mathrm{mM}$ potassium phosphate buffer, $\mathrm{pH} 7.4$ at $37^{\circ} \mathrm{C}$. After a 3 min pre-incubation, reactions were initiated with $200 \mu \mathrm{M}$ NADH (final volume $200 \mu \mathrm{L}$ ). The loss of absorbance of DCIP was monitored at $600 \mathrm{~nm}$ using a Perkin Elmer Victor $3 \mathrm{~V}$ microplate reader for $5 \mathrm{~min}$ at $37^{\circ} \mathrm{C}$, and then rotenone was added (final concentration $1 \mu \mathrm{M}$ ) with continual absorbance monitoring for an additional $5 \mathrm{~min}$. Rates were linear with respect to time and protein concentrations under these conditions. The rate of DCIP reduction was calculated based on the reported epsilon $\left(19.1 \mathrm{mM}^{-1} \mathrm{~cm}^{-1}\right)^{(\text {Janssen et al. 2007) }}$. The final Complex I rate was given as the difference between the total (uninhibited) rate and the rotenoneinsensitive rate.

\subsection{Succinate dehydrogenase (Complex II) activity assay}

Complex II-dependent conversion of succinate to fumarate was measured indirectly through ubiquinone reduction, which ultimately reduced DCIP. For reactions, mitochondria $(8 \mu \mathrm{g} / \mathrm{mL}$ protein) were incubated with $1 \mathrm{mg} / \mathrm{mL}$ bovine serum albumin, $2 \mathrm{mM}$ EDTA, $0.2 \mathrm{mM}$ ATP, 80 
$\mu \mathrm{M}$ DCIP, $50 \mu \mathrm{M}$ decylubiquinone, $3 \mu \mathrm{M}$ rotenone (Complex I inhibitor) and $1 \mu \mathrm{M}$ antimycin-A (Complex III inhibitor) in $80 \mathrm{mM}$ potassium phosphate buffer, $\mathrm{pH} 7.4$ at $37^{\circ} \mathrm{C}$. After a $10 \mathrm{~min}$ pre-incubation, reactions were initiated with $10 \mathrm{mM}$ succinate and $300 \mu \mathrm{M}$ potassium cyanide (Complex IV inhibitor) in a final volume $200 \mu \mathrm{L}$. The loss of absorbance of DCIP was monitored at $600 \mathrm{~nm}$ using a Perkin Elmer Victor $3 \mathrm{~V}$ microplate reader for $5 \mathrm{~min}$ at $37^{\circ} \mathrm{C}$. Rates were linear with respect to time and protein concentrations under these conditions. The final Complex II rate was calculated using the extinction coefficient for DCIP $\left(19.1 \mathrm{mM}^{-1} \mathrm{~cm}^{-}\right.$ $\left.{ }^{1}\right)($ Janssen et al. 2007).

\subsection{Cytochrome bc1 complex (Complex III) activity assay}

Complex III activity was measured as a function of cytochrome $c$ (cyt $c$ ) reduction by monitoring the change (increase) in its absorbance. For reactions, mitochondria $(2.5 \mu \mathrm{g} / \mathrm{mL}$ protein) were incubated with $1 \mathrm{mg} / \mathrm{mL}$ BSA, $0.5 \mathrm{mM}$ potassium cyanide (Complex IV inhibitor), $50 \mu \mathrm{M}$ decylubiquinone, $1 \mu \mathrm{g} / \mathrm{mL}$ rotenone (Complex I inhibitor), and $80 \mathrm{mM}$ succinate for 5 min at $37^{\circ} \mathrm{C}$. This pre-incubation allowed Complex II (with an excess of succinate) to convert decylubiquinone to reduced decylubiquinol. Then the reaction of interest was initiated with 60 $\mu \mathrm{M}$ (oxidized) cyt $c$ and the absorbance at $550 \mathrm{~nm}$ was measured for $5 \mathrm{~min}$ on a Biotek Synergy 2 microplate reader. Under these conditions, product formation was linear with respect to time and protein concentration and was not impacted by longer pre-incubation or increases in decylubiquinone or succinate concentrations. The final Complex III rate was determined using the published extinction coefficient for cyt $c\left(18.7 \mathrm{mM}^{-1} \mathrm{~cm}^{-1}\right)$ (Kirby et al. 2007).

\subsection{Cytochrome $c$ oxidase (Complex IV) activity assay}


The oxidation of cyt $c$ by Complex IV was measured directly by measuring the decrease in absorbance of reduced cyt $c$. For reactions, mitochondria $(2.5 \mu \mathrm{g} / \mathrm{mL}$ protein) were incubated with $0.45 \mathrm{mM}$ n-dodecylmaltocyde in $20 \mathrm{mM}$ potassium phosphate buffer, $\mathrm{pH}$ 7.4. After a $3 \mathrm{~min}$ pre-incubation, the reaction was initiated upon addition of $30 \mu \mathrm{M}$ reduced cyt $c$ and the absorbance measured at $550 \mathrm{~nm}$ for 5 min on a Biotek Synergy 2 microplate reader. Under these conditions, the presence of the detergent n-dodecylmaltocyde activates Complex IV activity, and so product formation followed first-order reaction kinetics and was linear with respect to protein concentration(Birchmachin et al. 1994). Absorbances were converted to product concentrations using the extinction coefficient for cyt $c\left(18.7 \mathrm{mM}^{-1} \mathrm{~cm}^{-1}\right)$ (Kirby et al. 2007), and apparent kinetic rate constants were determined using a non-linear fit to a one-phase exponential in the statistical software package GraphPad Prism 5.0 (La Jolla, CA).

\subsection{Blue Native Gel Electrophoresis (BNE) for isolation of individual complexes}

Blue native page electrophoresis is an efficient way to cleanly isolate intact mitochondrial respiratory protein complexes(Nijtmans et al. 2002). For preparation of samples, mitochondria were first thawed and pelleted by centrifugation at $10,000 \mathrm{x} g$ for $10 \mathrm{~min}$ at $4^{\circ} \mathrm{C}$. The pellet was then resuspended in Mitochondrial Extraction Buffer (0.75 M aminocaproic acid in $50 \mathrm{mM}$ BisTris, $\mathrm{pH} 7.0$ ) and lauryl maltoside was added to a final concentration of $1.33 \%$. The mixture was incubated on ice for $15 \mathrm{~min}$ with agitation at $5 \mathrm{~min}$ intervals. After $15 \mathrm{~min}$, the mixture was centrifuged at 10,000 $\mathrm{x} g$ for 10 min at $4^{\circ} \mathrm{C}$ and supernatant (Mitochondrial Extract, ME) collected. The protein concentration of the ME was determined using the Bradford assay(Bradford 1976), and $40 \mu \mathrm{g}$ of ME was then added to Coumassie Blue G250 (final 0.32\%) and glycerol (final $0.85 \%$ ) in a final volume of $23.5 \mu \mathrm{L}$. This mixture was loaded onto a pre-cast NativePAGE ${ }^{\mathrm{TM}}$ Novex ${ }^{\mathrm{TM}} 3-12 \%$ Bis-Tris Protein Gel, which was then run using High Blue 
Cathode buffer (50 mM Tricene, 15 mM Bis-Tris, $\mathrm{pH} 7.0$ with $0.02 \%$ Coumassie Blue G250) and Anode buffer (50mM Bis-Tris, pH 7.0) for $60 \mathrm{~min}$ at 40V. Following, the High Blue Cathode buffer was exchanged for Low Blue Cathode buffer (50 mM Tricene, 15 mM Bis-Tris, $\mathrm{pH} 7.0$ with $0.002 \%$ Coumassie Blue G250) and the gel run was continued at $140 \mathrm{~V}$ for 3 additional hr. The gel was then visualized with Coumassie Blue stain.

\subsection{Proteomics}

The mitochondrial respiratory protein complexes were cut into $2 \mathrm{~mm}$ band slices and subjected to in-gel trypsin digestion. Gel slices were destained in 50\% methanol, $100 \mathrm{mM}$ ammonium bicarbonate, followed by reduction in $10 \mathrm{mM}$ Tris[2-carboxyetyhyl]phosphine. Gel slices were then dehydrated in acetonitrile, followed by addition of $100 \mathrm{ng}$ of sequencing grade porcine trypsin (Promega, Madison, WI) in $100 \mathrm{mM}$ ammonium bicarbonate and incubation at 37C for $12-16 \mathrm{~h}$. Peptides were acidified in $0.1 \%$ formic acid (Fluka, Milwaukee, WI). Tryptic peptides were analyzed by high resolution tandem mass spectrometry with a Thermo Fusion Tribrid Orbitrap mass spectrometer coupled to a Waters nanoACQUITY LC system. Proteins were identified from MS/MS spectra by using de novo sequencing in PEAKS Studio 8.0 (Rapid Communications in Mass Spectrometry, 17(20): 2337-2342. 2003. PEAKS: Powerful Software for Peptide De Novo Sequencing by MS/MS.) followed by a customized PeaksDB search of the UniprotKB/Swiss-Prot database restricted to Mus musculus (79225 entries). The search parameters included a parent mass error tolerance of $5.0 \mathrm{ppm}$, fragment mass error tolerance of 0.5 Da, allowed 3 missed cleavages by trypsin, and variable modifications including THB (104.05), HB (70.04), HBE (86.04), PYR (87.04), PYR (86.04), and GSH-BDE (393.12) on C and H. A total of 4794 proteins were identified by PeaksDB. 


\subsection{Statistical Methods}

All statistical tests were performed using GraphPad Prism 5.0 (La Jolla, CA). Specifically, kinetic data were fit using linear or nonlinear regression analysis. Population means of activity were compared using Student's unpaired t-tests with two-tailed p-values. Correlations between activities of different enzymes were compared in the butadiene-exposed mice using Spearman correlation.

\section{Results}

\subsection{Microsomal CYP2E1 activity is reduced after butadiene exposure}

CYP2E1 activity assays using 4-nitrophenol as a marker revealed different regulation of erCYP2E1 (microsomal 4-nitrophenol activity) and mtCYP2E1 (4-nitrophenol hydroxylation in mitochondrial fractions) in response to butadiene exposure in the mice (Figure 2). There was a significant $(\mathrm{p}<0.0001)$ decrease in CYP2E1 activity in microsomes after butadiene exposure. erCYP2E1 activity in the population of air-exposed mice averaged $1.9 \pm 0.17 \mathrm{nmol} / \mathrm{min} / \mathrm{mg}$ protein, mean $\pm \mathrm{SEM}$, while that for butadiene-exposed mice was $1.1 \pm 0.059 \mathrm{nmol} / \mathrm{min} / \mathrm{mg}$ protein. By contrast, mtCYP2E1 activity did not significantly change $(\mathrm{p}=0.87)$ after butadiene exposure. $\mathrm{mtCYP} 2 \mathrm{E} 1$ activity in air-exposed population averaged $0.87 \pm 0.042 \mathrm{nmol} / \mathrm{min} / \mathrm{mg}$ protein and that for the butadiene-exposed population was $0.86 \pm 0.080 \mathrm{nmol} / \mathrm{min} / \mathrm{mg}$ protein.

\subsection{Butadiene exposure increases mtDNA content and does not induce mtDNA breaks}

Upon butadiene exposure, we observed a slight but statistically significant $(\mathrm{p}<0.05)$ increase in mitochondrial DNA using RT-PCR amplification of mtDNA (Cox-2) compared to nuclear 
DNA ( $\beta$-actin) in a subset of 11 randomly-selected matched control and 200-ppm butadieneexposed samples (Figure 3, Panel A). To test if the observed increase in mtDNA was due to synthesis of broken DNA pieces, the integrity of the DNA was measured using long and short mtDNA amplification in 5 samples. The ratio of long (13 kbp) to short mtDNA (200 bp) amplification did not change between the air- and butadiene- exposed animals (Figure 3, Panel B), indicating a lack of DNA breaks or major deletions with butadiene exposure. Additionally, the amplified long DNA synthesis products showed a single band at $13 \mathrm{kbp}$ on an agarose gel corresponding to fully extended product and lacked any visible partial synthesis products (data not shown).

\subsection{Mitochondrial respiratory complexes I, II, and IV show impaired activity after butadiene exposure}

Mitochondrial function is often assessed using direct measurement of respiration; however, these measurements require fresh (non-frozen) tissue due to a loss of membrane integrity in the freezing process. However, mitochondrial respiratory complexes I, II, III, and IV remain intact and retain activity after flash freezing and proper storage at $-80^{\circ} \mathrm{C}$ (Kirby et al. 2007; Thorburn et al. 2004). Therefore, in this study, the in vitro activities of each individual complex were measured using well-established spectrophotometric assays(Birchmachin et al. 1994; Brusque et al. 2002; Janssen et al. 2007; Kirby et al. 2007; Prasad and Muralidhara 2014). When comparing the populations of air- and butadiene- exposed mice, there was a significant $25-30 \%$ decrease $(\mathrm{p}<0.0001)$ in Complex I activity (Figure 4, Panel A), Complex II Activity (Figure 4, Panel B), and Complex IV activity (Figure 4, Panel D) following butadiene exposure. By contrast, there was no significant change in the mean for Complex III activity (Figure 4, Panel C), despite a significant increase in the variability of the population (F-test, $\mathrm{p}<0.0001)$. 


\subsection{Increased mitochondrial CYP2E1 activity correlates with decreased mitochondrial respiratory complex activity in butadiene-exposed mice}

To assess the importance of CYP2E1 in mediating butadiene-induced effects, mtCYP2E1 and erCYP2E1 activities for oxidation of 4-nitrophenol were correlated to the in vitro catalytic rates of the mitochondrial respiratory complexes in air- and butadiene-exposed mice. As shown in Figure 5 and Table 1, mtCYP2E1 activity negatively correlated with Complex I, II, III, and IV activity in butadiene-exposed animals based on significant Spearman correlation values. By contrast, erCYP2E1 only correlated weakly with Complex III activity in butadiene-exposed mice. There were no significant correlations of CYP2E1 activity in either organelle with mitochondrial respiratory complex activities in air-exposed animals. Consequently, mtCYP2E1 likely plays an important role in butadiene-derived mitochondrial damage.

\subsection{Activity of individual mitochondrial respiratory complexes correlate with one another after butadiene exposure}

We correlated the activities of mitochondrial respiratory complexes to one another in air- and butadiene-exposed mice to assess if complexes were similarly impaired within the same mouse after butadiene exposure. The complex activities were positively correlated after butadiene exposure (Figure 6, Table 2) but no significant correlation was observed between complex activities in air-exposed mice. Consequently, butadiene exposure caused a similar impairment across the mitochondrial respiratory chain in individually exposed animals.

3.6 BN-PAGE and proteomics approaches reveal no loss of complex integrity and no detected enrichment of butadiene-derived protein adducts with exposure 
Mitochondrial toxicity may reflect changes in the ratio of mitochondrial respiratory complexes and/or their compositions of subunits, along with possible covalent binding of reactive metabolites to proteins. Potential disruption of complexes was visualized through blue native polyacrylamide electrophoresis gel electrophoresis (BN-PAGE). Qualitatively, the gel separation of mitochondrial complexes from air-exposed mice did not differ from the butadieneexposed mice (Fig. S1, Supplemental Data). Semi-quantitative densitometric analysis of the gel lanes revealed no significant changes with butadiene exposure in the band densities corresponding to the complexes with the same quantity of protein loaded in each lane (data not shown). Finally, mass spectrometric analysis was performed to measure butadiene metabolitederived modifications to the proteins. Spectral data from mitochondrial fractions were searched for Complex I to IV proteins. Peptides were found for 41 of 44, 4 of 4, 10 of 10, 12 of 20 and 15 of 18 proteins from Complex I, II, III, IV and V respectively (Table S1, Supplemental Data). The average protein coverage was $53 \%$. The search was focused on peptides corresponding to important respiratory complex proteins including ubiquinone reductase (complex I), succinate dehydrogenase (complex II), cytochrome c (electron carrier), and cytochrome c oxidase (complex IV). Subsequently, the spectra were searched for peptides modified by butadiene metabolites. More specifically, the search focused on peptide masses (i) corresponding to proteins of interest, (ii) were in the data set and (iii) had mass addition corresponding binding for butadiene metabolites. The search did not reveal any significant butadiene metabolite-modified peptides (Swenberg et al. 2011) when comparing air (control) to butadiene exposed mice (Fig. S2 and Table S2, Supplemental Data). 


\section{Discussion}

Herein, we demonstrate the first ex vivo evidence for the importance of mtCYP2E1 in triggering exposure-induced mitochondrial dysfunction using the genetically diverse Collaborative Cross mouse model. The mean overall activity for mitochondrial complexes decreased in response to butadiene exposure, suggesting damage to mitochondrial respiratory complexes. Correlation studies showed that impairment of mitochondrial respiratory complex activity in butadiene-exposed mice was inversely correlated with mtCYP2E1 activity, suggesting a mechanistic link between mtCYP2E1 activity and mitochondrial dysfunction. Importantly, no correlation was observed between erCYP2E1 and these decreased activities. Therefore, mitochondrial but not microsomal CYP2E1 activity may be a more suitable predictor for mitochondrial toxicological response to this exposure. Based on these findings, mtCYP2E1 could play a major role in bioactivating pollutants in situ to cause damage to mitochondrial proteins and hence, mitochondrial dysfunction.

Previous efforts to demonstrate a role for mtCYP2E1 relied on overexpression of mtCYP2E1 in cell culture; by contrast, this study exploited the natural variation in mtCYP2E1 and erCYP2E1 activity in a genetically diverse mouse population to assess its role on downstream effects of butadiene metabolism under ex vivo conditions. CYP2E1 is highly evolutionarily conserved among vertebrates and shares a high sequence identity between humans, rats, and mice(Martignoni et al. 2006); not surprisingly, we found that distribution of CYP2E1 targeted to mitochondria and endoplasmic reticulum varied among genetically diverse mice similar to variation previously shown in human liver tissues(Bansal et al. 2013). Although in our mouse model lifestyle and environment are kept constant, and variation in CYP2E1 activity can be attributed to genetic diversity, in humans CYP2E1 activity the result of complex lifestyle- 
exposure-gene-interactions. The significant variation in CYP2E1 activity in the two compartments within the mouse population, however, provides a suitable dynamic range for identifying its role from different organelles in driving butadiene-induced damage of mitochondrial respiratory proteins as revealed through correlative studies.

CYP2E1 activity for 4-nitrophenol oxidation revealed an overall decrease in the population mean microsomal erCYP2E1 following exposure to butadiene. This finding is somewhat unexpected due to the tendency of most CYP2E1 substrates to cause overall induction of CYP2E1 through multiple mechanisms including stabilization against proteasomal degradation(Koop and Tierney 1990). In this case, butadiene exposure may downregulate erCYP2E1 expression at the transcription or translational level leading to the observed lowered activities. Alternatively, the reactive metabolites might directly affect enzyme activity through inhibition as reported previously(Hartman et al. 2014) or covalent binding to CYP2E1 at sites potentially important for enzyme activity(Boysen et al. 2007b).

In contrast to erCYP2E1, mtCYP2E1 activity did not significantly change following butadiene exposure. This finding highlights an important and emerging feature suggesting different mechanisms for regulation of mtCYP2E1 and mtCYP2E1 expression and activity. Previous cell culture studies have shown that mtCYP2E1 localizes to the inner membrane of mitochondria and therefore is inaccessible for proteasomal degradation. In fact, in our studies, the half-life of mtCYP2E1 is about 5-fold longer than the half-life published for erCYP2E1 ( $>48$ h, unpublished observation versus 6-12 h, respectively) (Emery et al. 1999; Roberts et al. 1994; Roberts et al. 1995). Given the stability of mtCYP2E1 against degradation, it is conceivable that there was increased degradation of erCYP2E1 in response to the exposure, which did not impact 
the mitochondrial form. If the reduction in CYP2E1 activity is an overall protective mechanism, it would fail to safeguard mitochondria against CYP2E1-depenedent damage

To our knowledge this is the first study demonstrating butadiene-induced mitochondrial dysfunction. 1,3-Butatdiene exposures decreased the mean respiratory complex activities in the population of Collaborative Cross mice. Correlative studies revealed impairment in activities of all 4 complexes, such that the complex activities were correlated after butadiene exposure (but not in air-exposed animals). These experiments revealed that some mice in the population were resistant to butadiene-induced mitochondrial dysfunction, showing normal levels of activity (comparable to the mean of the air-exposed population) in each complex. By contrast, others were susceptible to butadiene-induced damage to one or more respiratory complex. Further correlative studies showed that mtCYP2E1 was negatively correlated with respiratory complex activities, suggesting that mtCYP2E1 may be mechanistically linked to exposure-induced mitochondrial dysfunction.

The simplest mechanism to explain the correlation of mtCYP2E1 to butadiene-induced mitochondrial dysfunction is through CYP2E1 generation of reactive epoxide metabolites, which can bind covalently to cellular nucleophiles, including amino acid residues in the respiratory complex proteins. To test this possibility, we performed exploratory proteomic experiments with three representative samples from each of the following groups: control (air-exposed) mice, butadiene-exposed mice with normal respiratory complex activities, and butadiene-exposed mice with impaired respiratory complex activities. Unfortunately, the expected butadiene-derived protein modifications were not observed in the butadiene-exposed population. More targeted experiments are needed to determine if the reduction in protein activity is due to binding of reactive butadiene metabolites or if it is an indirect effect (through increased reactive oxygen and 
reactive nitrogen species, for example). Although more of a long term impact, CYP2E1 generation of reactive metabolites could also damage mitochondrial DNA leading to altered expression of mitochondrial proteins and/or mitochondrial dynamics. Nevertheless, preliminary studies on representative samples indicated a lack of gene deletions with mtDNA and possible increase in content, suggesting butadiene exposure could stimulate mitochondrial replication. This mechanism may compensate for decreased mitochondrial function as indicated by decrease in the activity of respiratory proteins; however, future studies are necessary to validate these findings in support of that possibility.

\section{Concluding remarks:}

CYP2E1 has been recognized since its discovery for its potential role in xenobiotic exposureinduced toxicity. However, differential localization of CYP2E1 in mitochondria and endoplasmic reticulum may have complicated interpretation of CYP2E1-dependent toxicity. Therefore, delineation of the activities in each compartment is essential to assess organelle-specific toxicities such as mitochondrial dysfunction. Future studies should focus on further delineating the roles of mtCYP2E1 and erCYP2E1 and the impact of localization in each organelle on cellular toxicity and organismal pathogenesis. This strategy may reveal CYP2E1 levels in each compartment as a risk factor for certain exposures, and allow better risk assessment for the metabolic activation of CYP2E1 substrates in toxicological mechanisms. Lastly using the Collaborative Cross mouse population shows that BD significantly alters erCYP2E1 in most strains. 


\section{Acknowledgements}

This work was supported in part by NIEHS of the National Institutes of Health (R21ES023046 F32ES027306, R21ES025268, R21DA041822, R01GM106024, UL1TR000039, S10OD018445 and, P20GM103429, P20GM103625, P20GM121293, and P30ES006676), National Science Foundation Graduate Research Fellowship Program (DGE1452779), and a bridging grant from the UAMS (GPM). The authors acknowledge the technical support of Dr. Dwayne Carter, Dr. Daniel J. Hochman, Dr. Anita L. Reno, KarryAnne K. Belanger Nicholas L. Hallberg, Spotswood D. Miller, Barbara A. Rolls, and Walter C. Spear, in conducting the exposure studies and the UAMS Proteomics Facility for mass spectrometric support. 


\title{
Figure Legends
}

Figure 1. Metabolic pathways of 1,3-butadiene. Displayed are epoxide metabolites generated by CYP2E1 which can undergo nucleophilic attack by cellular proteins and DNA to form covalent adducts. Alternatively, epoxide groups can be hydrolyzed by cellular epoxide hydrolase (EH) as shown.

Figure 2. Butadiene exposure decreases microsomal CYP2E1 activity in genetically diverse population of mice. Panel A represents microsomal CYP2E1 activity and Panel B represents mitochondrial activity in air-exposed (CTRL) and 200 ppm butadiene-exposed (BD-exposed) mice. Each data point represents the mean activity in each genetically diverse mouse in the population. Reactions were performed at least three times with $0.1 \mathrm{mg} / \mathrm{mL}$ microsomes or 0.25 $\mathrm{mg} / \mathrm{mL}$ mitochondria, $50 \mu \mathrm{M}$ 4-nitrophenol, and $1 \mathrm{mM} \mathrm{NADPH}$ at $37^{\circ} \mathrm{C}$ and $\mathrm{pH} 7.4$. Asterisks represent statistical significance based on the Student's unpaired t-test, ***, p<0.001; n.s., not significant, $\mathrm{p}>0.05$.

\author{
Figure 3. Mitochondrial DNA content increases yet integrity does not change for \\ butadiene-exposed mice. In panel A, mtDNA content was assessed using real-time PCR \\ amplification of the mitochondrial Cox-1 gene compared to the nuclear control $\beta$-actin. In panel \\ $\mathrm{B}$, mtDNA integrity was determined by comparing a long amplification of a $10 \mathrm{kpb}$ segment of \\ mtDNA compared to a short $117 \mathrm{bp}$ segment of mtDNA. Asterisks represent statistical \\ significance based on the Student's unpaired t-test, *, p<0.05; n.s., not significant, $p>0.05$.
}

\author{
Figure 4. Butadiene-exposed mice showed impaired mitochondrial respiratory complex \\ activity. Panel A represents mitochondrial Complex I activity; Panel B, mitochondrial Complex \\ II activity; Panel C, mitochondrial Complex III activity; Panel D, mitochondrial Complex IV
}


activity. Each data point represents the mean activity in each genetically diverse mouse in the population. Reactions were performed at least three times with saturating substrate concentrations and inhibitors of the other complexes when appropriate. Full reaction conditions are described in Materials and Methods. Asterisks represent statistical significance based on the Student's unpaired t-test, $* * *, p<0.001 ;$ n.s., not significant, $\mathrm{p}>0.05$.

\author{
Figure 5. MtCYP2E1 activity negatively correlates with mitochondrial respiratory complex \\ activities in butadiene-exposed mice. Correlations were performed between mtCYP2E1 and \\ each mitochondrial respiratory complex with a Spearman correlation analysis using GraphPad \\ Prism $5^{\circledR}$ software (La Jolla, CA); Panel A, mtCYP2E1 vs. Complex I; Panel B, mtCYP2E1 vs. \\ Complex II; Panel C, mtCYP2E1 vs. Complex III; Panel D, mtCYP2E1 vs. Complex IV. The \\ significance of the correlations are summarized in Table 1.
}

\author{
Figure 6. Mitochondrial respiratory complex activities positively correlate with one \\ another after butadiene exposure. Correlations were performed between each mitochondrial \\ respiratory complex with a Spearman correlation analysis using GraphPad Prism $5^{\circledR}$ software (La \\ Jolla, CA); Panel A, Complexes I and II; Panel B, Complexes I and III; Panel C, Complexes I \\ and IV; Panel D, Complexes II and III; Panel E, Complexes III and IV; Panel F, Complexes II \\ and IV. The significance of each correlation is given in Table 2.
}




\section{References}

Abdelmegeed, M.A., Ha, S.K., Choi, Y., Akbar, M. and Song, B.J. 2015. Role of CYP2E1 in mitochondrial dysfunction and hepatic tissue injury in alcoholic and non-alcoholic diseases. Current molecular pharmacology.

Avadhani, N.G., Sangar, M.C., Bansal, S. and Bajpai, P. 2011. Bimodal targeting of cytochrome P450s to endoplasmic reticulum and mitochondria: the concept of chimeric signals. The FEBS journal 278, 4218-4229.

Bai, J. and Cederbaum, A.I. 2006. Overexpression of CYP2E1 in Mitochondria Sensitizes HepG2 Cells to the Toxicity Caused by Depletion of Glutathione. Journal of Biological Chemistry 281, 5128-5136.

Bansal, S., Anandatheerthavarada, H.K., Prabu, G.K., Milne, G.L., Martin, M.V., Guengerich, F.P. and Avadhani, N.G. 2013. Human cytochrome P450 2E1 mutations that alter mitochondrial targeting efficiency and susceptibility to ethanol-induced toxicity in cellular models. The Journal of biological chemistry 288, 12627-12644.

Bansal, S., Liu, C.P., Sepuri, N.B., Anandatheerthavarada, H.K., Selvaraj, V., Hoek, J., Milne, G.L., Guengerich, F.P. and Avadhani, N.G. 2010. Mitochondria-targeted cytochrome P450 2E1 induces oxidative damage and augments alcohol-mediated oxidative stress. The Journal of biological chemistry 285, 24609-24619.

Birchmachin, M.A., Briggs, H.L., Saborido, A.A., Bindoff, L.A. and Turnbull, D.M. 1994. An Evaluation of the Measurement of the Activities of Complexes I-IV in the Respiratory Chain of Human Skeletal Muscle Mitochondria. Biochemical Medicine and Metabolic Biology 51, 35-42.

Boysen, G., Georgieva, N.I., Upton, P.B., Walker, V.E. and Swenberg, J.A. 2007a. N-terminal globin adducts as biomarkers for formation of butadiene derived epoxides. Chem Biol Interact $166,84-92$.

Boysen, G., Scarlett, C.O., Temple, B., Combs, T.P., Brooks, N.L., Borchers, C.H. and Swenberg, J.A. 2007b. Identification of covalent modifications in P450 2E1 by 1,2-epoxy-3butene in vitro. Chem Biol Interact 166, 170-175.

Bradford, M.M. 1976. A rapid and sensitive method for the quantitation of microgram quantities of protein utilizing the principle of protein-dye binding. Analytical Biochemistry 72, 248-254.

Brusque, A.M., Borba Rosa, R., Schuck, P.F., Dalcin, K.B., Ribeiro, C.A., Silva, C.G., Wannmacher, C.M., Dutra-Filho, C.S., Wyse, A.T., Briones, P. and Wajner, M. 2002. Inhibition of the mitochondrial respiratory chain complex activities in rat cerebral cortex by methylmalonic acid. Neurochem Int 40, 593-601.

Chesler, E.J., Miller, D.R., Branstetter, L.R., Galloway, L.D., Jackson, B.L., Philip, V.M., Voy, B.H., Culiat, C.T., Threadgill, D.W., Williams, R.W., Churchill, G.A., Johnson, D.K. and Manly, K.F. 2008. The Collaborative Cross at Oak Ridge National Laboratory: developing a powerful resource for systems genetics. Mammalian genome : official journal of the International Mammalian Genome Society 19, 382-389. 
Cho, S.-H. and Guengerich, F.P. 2012. Conjugation of Butadiene Diepoxide with Glutathione Yields DNA Adducts in Vitro and in Vivo. Chem Res Toxicol 25, 706-712.

Churchill, G.A., Airey, D.C., Allayee, H., Angel, J.M., Attie, A.D., Beatty, J., Beavis, W.D., Belknap, J.K., Bennett, B., Berrettini, W., Bleich, A., Bogue, M., Broman, K.W., Buck, K.J., Buckler, E., Burmeister, M., Chesler, E.J., Cheverud, J.M., Clapcote, S., Cook, M.N., Cox, R.D., Crabbe, J.C., Crusio, W.E., Darvasi, A., Deschepper, C.F., Doerge, R.W., Farber, C.R., Forejt, J., Gaile, D., Garlow, S.J., Geiger, H., Gershenfeld, H., Gordon, T., Gu, J., Gu, W., de Haan, G., Hayes, N.L., Heller, C., Himmelbauer, H., Hitzemann, R., Hunter, K., Hsu, H.C., Iraqi, F.A., Ivandic, B., Jacob, H.J., Jansen, R.C., Jepsen, K.J., Johnson, D.K., Johnson, T.E., Kempermann, G., Kendziorski, C., Kotb, M., Kooy, R.F., Llamas, B., Lammert, F., Lassalle, J.M., Lowenstein, P.R., Lu, L., Lusis, A., Manly, K.F., Marcucio, R., Matthews, D., Medrano, J.F., Miller, D.R., Mittleman, G., Mock, B.A., Mogil, J.S., Montagutelli, X., Morahan, G., Morris, D.G., Mott, R., Nadeau, J.H., Nagase, H., Nowakowski, R.S., O'Hara, B.F., Osadchuk, A.V., Page, G.P., Paigen, B., Paigen, K., Palmer, A.A., Pan, H.J., Peltonen-Palotie, L., Peirce, J., Pomp, D., Pravenec, M., Prows, D.R., Qi, Z., Reeves, R.H., Roder, J., Rosen, G.D., Schadt, E.E., Schalkwyk, L.C., Seltzer, Z., Shimomura, K., Shou, S., Sillanpaa, M.J., Siracusa, L.D., Snoeck, H.W., Spearow, J.L., Svenson, K., Tarantino, L.M., Threadgill, D., Toth, L.A., Valdar, W., de Villena, F.P., Warden, C., Whatley, S., Williams, R.W., Wiltshire, T., Yi, N., Zhang, D., Zhang, M. and Zou, F. 2004. The Collaborative Cross, a community resource for the genetic analysis of complex traits. Nature genetics 36, 1133-1137.

Emery, M.G., Jubert, C., Thummel, K.E. and Kharasch, E.D. 1999. Duration of Cytochrome P450 2E1 (CYP2E1) Inhibition and Estimation of Functional CYP2E1 Enzyme Half-Life after Single-Dose Disulfiram Administration in Humans. Journal of Pharmacology and Experimental Therapeutics 291, 213-219.

Fleischer, S. and Kervina, M. 1974. Subcellular fractionation of rat liver. Methods in enzymology 31, 6-41.

Furda, A.M., Bess, A.S., Meyer, J.N. and Van Houten, B. 2012. Analysis of DNA damage and repair in nuclear and mitochondrial DNA of animal cells using quantitative PCR. Methods Mol Biol 920, 111-132.

Georgieva, N.I., Boysen, G., Bordeerat, N., Walker, V.E. and Swenberg, J.A. 2010. ExposureResponse of 1,2:3,4-Diepoxybutane-Specific N-Terminal Valine Adducts in Mice and Rats after Inhalation Exposure to 1,3-Butadiene. Toxicol Sci 115, 322-329.

Gregg, C., Kyryakov, P. and Titorenko, V.I. 2009. Purification of Mitochondria from Yeast Cells. Journal of Visualized Experiments : JoVE, 1417.

Hance, N., Ekstrand, M.I. and Trifunovic, A. 2005. Mitochondrial DNA polymerase gamma is essential for mammalian embryogenesis. Human molecular genetics 14, 1775-1783.

Hartman, J.H., Martin, H.C., Caro, A.A., Pearce, A.R. and Miller, G.P. 2015. Subcellular localization of rat CYP2E1 impacts metabolic efficiency toward common substrates. Toxicology $338,47-58$. 

alkenes toward CYP2E1 activity. Toxicology 318, 51-58.

Himmelstein, M.W., Acquavella, J.F., Recio, L., Medinsky, M.A. and Bond, J.A. 1997. Toxicology and Epidemiology of 1,3-Butadiene. Critical reviews in toxicology 27, 1-108.

Iraqi, F.A., Churchill, G. and Mott, R. 2008. The Collaborative Cross, developing a resource for mammalian systems genetics: a status report of the Wellcome Trust cohort. Mammalian genome : official journal of the International Mammalian Genome Society 19, 379-381.

Janssen, A.J.M., Trijbels, F.J.M., Sengers, R.C.A., Smeitink, J.A.M., van den Heuvel, L.P., Wintjes, L.T.M., Stoltenborg-Hogenkamp, B.J.M. and Rodenburg, R.J.T. 2007. Spectrophotometric Assay for Complex I of the Respiratory Chain in Tissue Samples and Cultured Fibroblasts. Clinical Chemistry 53, 729.

Kirby, D.M., Thorburn, D.R., Turnbull, D.M. and Taylor, R.W. 2007. Biochemical Assays of Respiratory Chain Complex Activity. Methods in cell biology, Academic Press, pp. 93-119.

Kirman, C.R., Albertini, R.J., Sweeney, L.M. and Gargas, M.L. 2010. 1,3-Butadiene: I. Review of metabolism and the implications to human health risk assessment. Critical reviews in toxicology 40 Suppl 1, 1-11.

Koivisto, P., Kilpelainen, I., Rasanen, I., Adler, I.D., Pacchierotti, F. and Peltonen, K. 1999. Butadiene diolepoxide- and diepoxybutane-derived DNA adducts at N7-guanine: a high occurrence of diolepoxide-derived adducts in mouse lung after 1,3-butadiene exposure. Carcinogenesis 20, 1253-1259.

Koivisto, P., Sorsa, M., Pacchierotti, F. and Peltonen, K. 1997. 32P-postlabelling/HPLC assay reveals an enantioselective adduct formation in $\mathrm{N} 7$ guanine residues in vivo after 1,3-butadiene inhalation exposure. Carcinogenesis 18, 439-443.

Koop, D.R., Morgan, E.T., Tarr, G.E. and Coon, M.J. 1982. Purification and characterization of a unique isozyme of cytochrome P-450 from liver microsomes of ethanol-treated rabbits. The Journal of biological chemistry $257,8472-8480$.

Koop, D.R. and Tierney, D.J. 1990. Multiple mechanisms in the regulation of ethanol-inducible cytochrome P450IIE1. BioEssays : news and reviews in molecular, cellular and developmental biology 12, 429-435.

Lieber, C.S. 1997. Cytochrome P-4502E1: its physiological and pathological role. Physiological reviews $77,517-544$.

Martignoni, M., Groothuis, G.M. and de Kanter, R. 2006. Species differences between mouse, rat, dog, monkey and human CYP-mediated drug metabolism, inhibition and induction. Expert Opinion on Drug Metabolism \& Toxicology 2, 875-894.

Meisinger, C., Sommer, T. and Pfanner, N. 2000. Purification of Saccharomcyes cerevisiae Mitochondria Devoid of Microsomal and Cytosolic Contaminations. Analytical Biochemistry 287, 339-342. 
Miller, G.P. 2008. Advances in the interpretation and prediction of CYP2E1 metabolism from a biochemical perspective. Expert Opinion on Drug Metabolism \& Toxicology 4, 1053-1064.

Morahan, G., Balmer, L. and Monley, D. 2008. Establishment of "The Gene Mine": a resource for rapid identification of complex trait genes. Mammalian genome : official journal of the International Mammalian Genome Society 19, 390-393.

Nijtmans, L.G., Henderson, N.S. and Holt, I.J. 2002. Blue Native electrophoresis to study mitochondrial and other protein complexes. Methods (San Diego, Calif.) 26, 327-334.

Prasad, S.N. and Muralidhara. 2014. Neuroprotective effect of geraniol and curcumin in an acrylamide model of neurotoxicity in Drosophila melanogaster: relevance to neuropathy. Journal of insect physiology 60, 7-16.

Roberts, B.J., Shoaf, S.E., Jeong, K.S. and Song, B.J. 1994. Induction of CYP2E1 in Liver, Kidney, Brain and Intestine During Chronic Ethanol Administration and Withdrawal: Evidence That CYP2E1 Possesses a Rapid Phase Half-Life of 6 Hours or Less. Biochemical and Biophysical Research Communications 205, 1064-1071.

Roberts, B.J., Song, B.-J., Soh, Y., Park, S.S. and Shoaf, S.E. 1995. Ethanol Induces CYP2E1 by Protein Stabilization: ROLE OF UBIQUITIN CONJUGATION IN THE RAPID DEGRADATION OF CYP2E1. Journal of Biological Chemistry 270, 29632-29635.

Robin, M.A., Anandatheerthavarada, H.K., Biswas, G., Sepuri, N.B., Gordon, D.M., Pain, D. and Avadhani, N.G. 2002. Bimodal targeting of microsomal CYP2E1 to mitochondria through activation of an N-terminal chimeric signal by cAMP-mediated phosphorylation. The Journal of biological chemistry 277, 40583-40593.

Robin, M.A., Anandatheerthavarada, H.K., Fang, J.K., Cudic, M., Otvos, L. and Avadhani, N.G. 2001. Mitochondrial targeted cytochrome P450 2E1 (P450 MT5) contains an intact N terminus and requires mitochondrial specific electron transfer proteins for activity. The Journal of biological chemistry 276, 24680-24689.

Robin, M.A., Sauvage, I., Grandperret, T., Descatoire, V., Pessayre, D. and Fromenty, B. 2005. Ethanol increases mitochondrial cytochrome P450 2E1 in mouse liver and rat hepatocytes. FEBS letters 579, 6895-6902.

Sangar, M.C., Bansal, S. and Avadhani, N.G. 2010. Bimodal targeting of microsomal cytochrome P450s to mitochondria: implications in drug metabolism and toxicity. Expert Opinion on Drug Metabolism \& Toxicology 6, 1231-1251.

Swenberg, J.A., Bordeerat, N.K., Boysen, G., Carro, S., Georgieva, N.I., Nakamura, J., Troutman, J.M., Upton, P.B., Albertini, R.J., Vacek, P.M., Walker, V.E., Sram, R.J., Goggin, M. and Tretyakova, N. 2011. 1,3-Butadiene: Biomarkers and application to risk assessment. Chem Biol Interact 192, 150-154.

Thorburn, D.R., Chow, C.W. and Kirby, D.M. 2004. Respiratory chain enzyme analysis in muscle and liver. Mitochondrion 4, 363-375. 
Threadgill, D.W., Hunter, K.W. and Williams, R.W. 2002. Genetic dissection of complex and quantitative traits: from fantasy to reality via a community effort. Mammalian genome : official journal of the International Mammalian Genome Society 13, 175-178.

Welsh, C.E., Miller, D.R., Manly, K.F., Wang, J., McMillan, L., Morahan, G., Mott, R., Iraqi, F.A., Threadgill, D.W. and de Villena, F.P. 2012. Status and access to the Collaborative Cross population. Mammalian genome : official journal of the International Mammalian Genome Society $23,706-712$. 
Table 1. Spearman correlation of mtCYP2E1 and erCYP2E1 activity with mitochondrial respiratory complex activities.

\begin{tabular}{|c|c|c|c|c|c|}
\hline Complex & Exposure & CYP2E1 Location & Spearman $r$ & $p$-value & Summary $^{a}$ \\
\hline \multirow{4}{*}{ Complex I } & \multirow{2}{*}{ Air Control } & Microsomes (ER) & 0.19 & 0.15 & n.s. \\
\hline & & Mitochondria & -0.087 & 0.52 & n.s. \\
\hline & 200-PPM & Microsomes (ER) & 0.11 & 0.44 & n.s. \\
\hline & Butadiene & Mitochondria & -0.27 & 0.046 & $*$ \\
\hline \multirow{4}{*}{ Complex II } & \multirow{2}{*}{ Air Control } & Microsomes (ER) & 0.045 & 0.74 & n.s. \\
\hline & & Mitochondria & -0.24 & 0.067 & n.s. \\
\hline & 200-PPM & Microsomes (ER) & -0.11 & 0.40 & n.s. \\
\hline & Butadiene & Mitochondria & -0.43 & 0.0013 & $* *$ \\
\hline \multirow{4}{*}{ Complex III } & \multirow{2}{*}{ Air Control } & Microsomes (ER) & -0.067 & 0.62 & n.s. \\
\hline & & Mitochondria & -0.080 & 0.55 & n.s. \\
\hline & 200-PРM & Microsomes (ER) & -0.31 & 0.0251 & $*$ \\
\hline & Butadiene & Mitochondria & -0.58 & $<0.0001$ & $* * *$ \\
\hline \multirow{4}{*}{ Complex IV } & \multirow{2}{*}{ Air Control } & Microsomes (ER) & 0.18 & 0.19 & n.s. \\
\hline & & Mitochondria & -0.076 & 0.58 & n.s. \\
\hline & 200-PPM & Microsomes (ER) & -0.22 & 0.10 & n.s. \\
\hline & Butadiene & Mitochondria & -0.52 & $<0.0001$ & $* * *$ \\
\hline
\end{tabular}

${ }^{\mathrm{a}}$ Asterisks represent summary of significance; *, $\mathrm{p}<0.05 ;{ }^{* *}, \mathrm{p}<0.01 ; * * *, \mathrm{p}<0.001$ 
Table 2. Spearman correlation of mitochondrial respiratory complex activities.

\begin{tabular}{|c|c|c|c|c|c|}
\hline Complex & Exposure & Correlation & Spearman $r$ & $p$-value & Summary $^{\mathrm{a}}$ \\
\hline \multirow{6}{*}{ Complex I } & \multirow{3}{*}{ Air Control } & Complex II & 0.12 & 0.39 & n.s. \\
\hline & & Complex III & 0.16 & 0.23 & n.s. \\
\hline & & Complex IV & 0.14 & 0.21 & n.s. \\
\hline & \multirow{3}{*}{ BD-Exposed } & Complex II & 0.48 & 0.0002 & $* * *$ \\
\hline & & Complex III & 0.35 & 0.012 & * \\
\hline & & Complex IV & 0.53 & $<0.0001$ & $* * *$ \\
\hline \multirow{4}{*}{ Complex II } & \multirow{2}{*}{ Air Control } & Complex III & 0.10 & 0.45 & n.s. \\
\hline & & Complex IV & 0.18 & 0.18 & n.s. \\
\hline & \multirow{2}{*}{ BD-Exposed } & Complex III & 0.80 & $<0.0001$ & $* * *$ \\
\hline & & Complex IV & 0.79 & $<0.0001$ & $* * *$ \\
\hline \multirow{2}{*}{ Complex III } & Air Control & Complex IV & 0.17 & 0.22 & n.s. \\
\hline & BD-Exposed & Complex IV & 0.34 & 0.014 & $*$ \\
\hline
\end{tabular}

${ }^{a}$ Asterisks represent summary of significance; *, $\mathrm{p}<0.05 ;{ }^{* *}, \mathrm{p}<0.01 ; * * *, \mathrm{p}<0.001$ 
Figure 1.

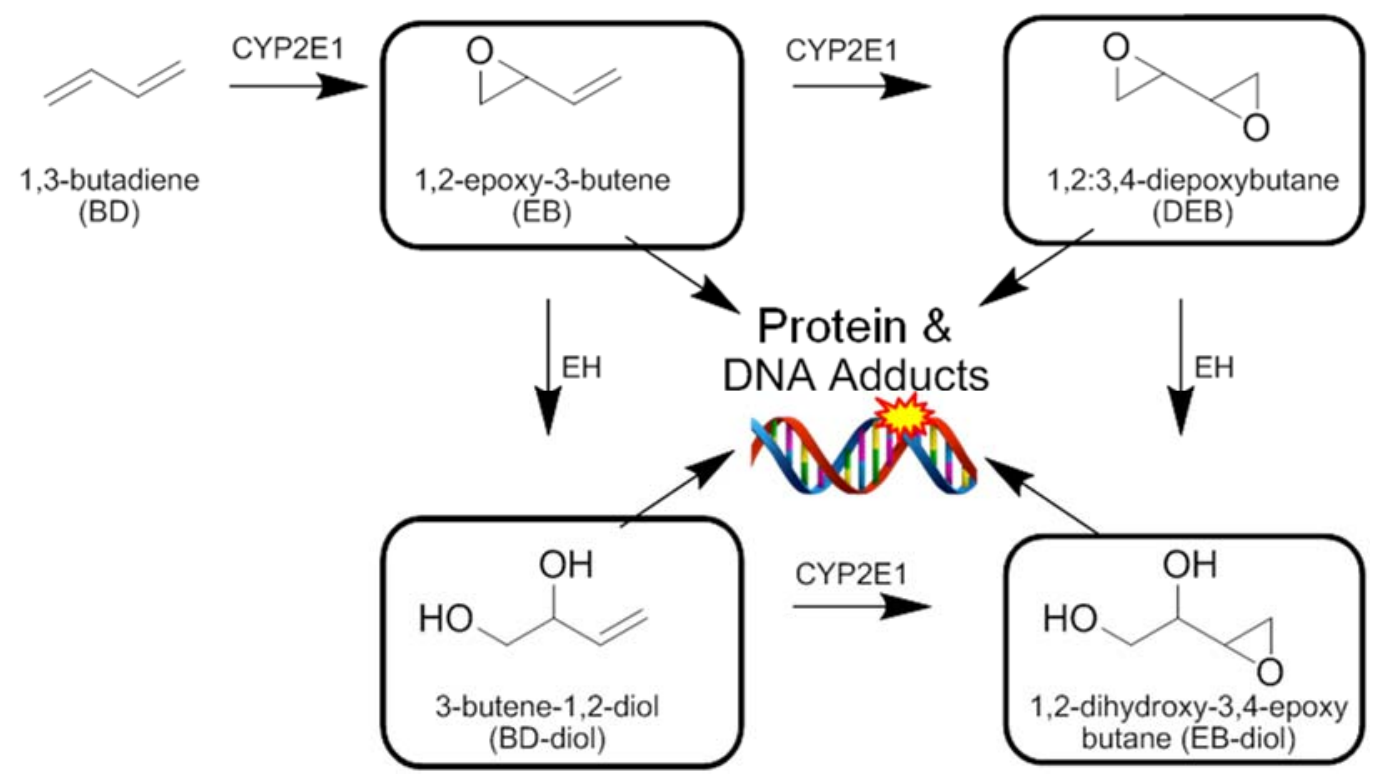


Figure 2
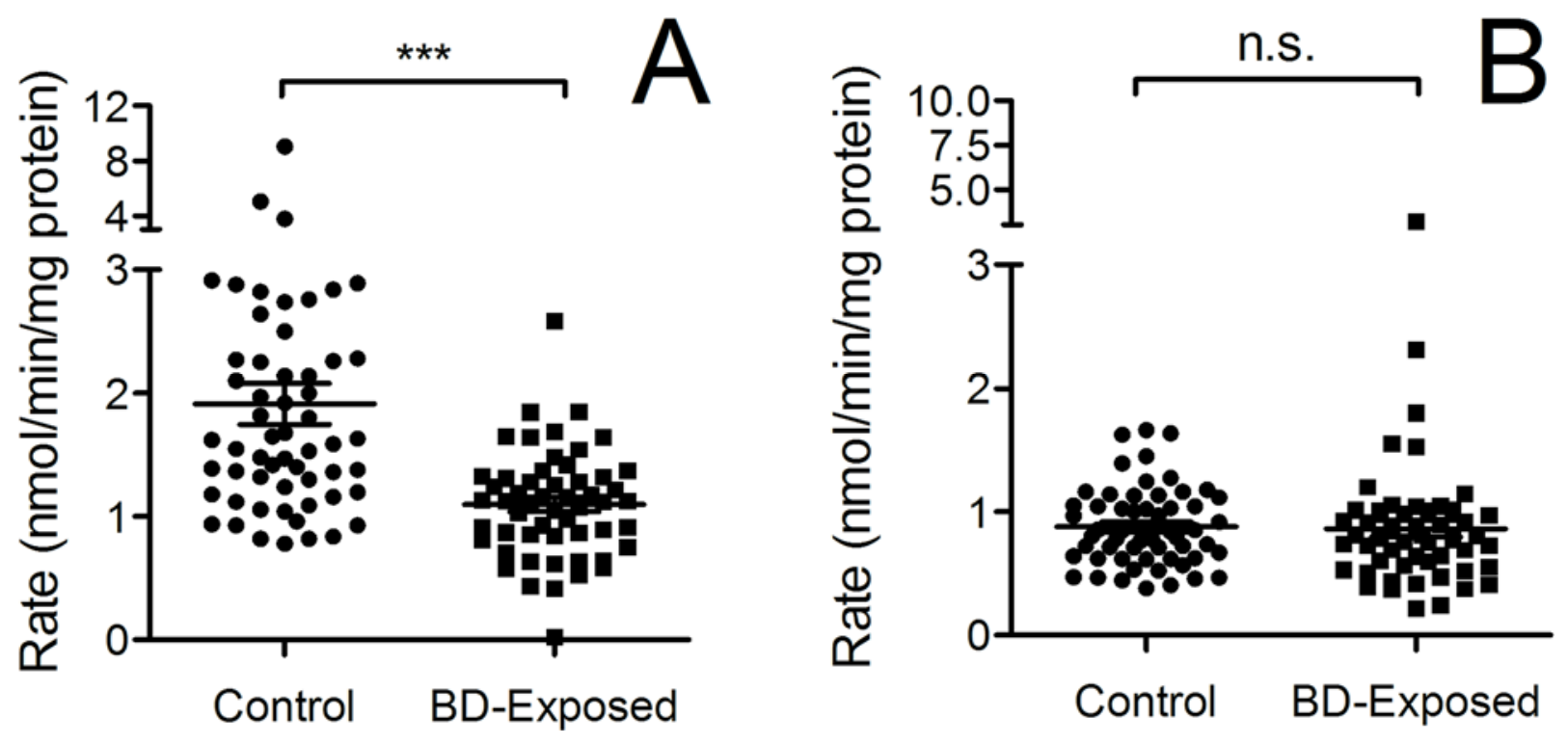
Figure 3
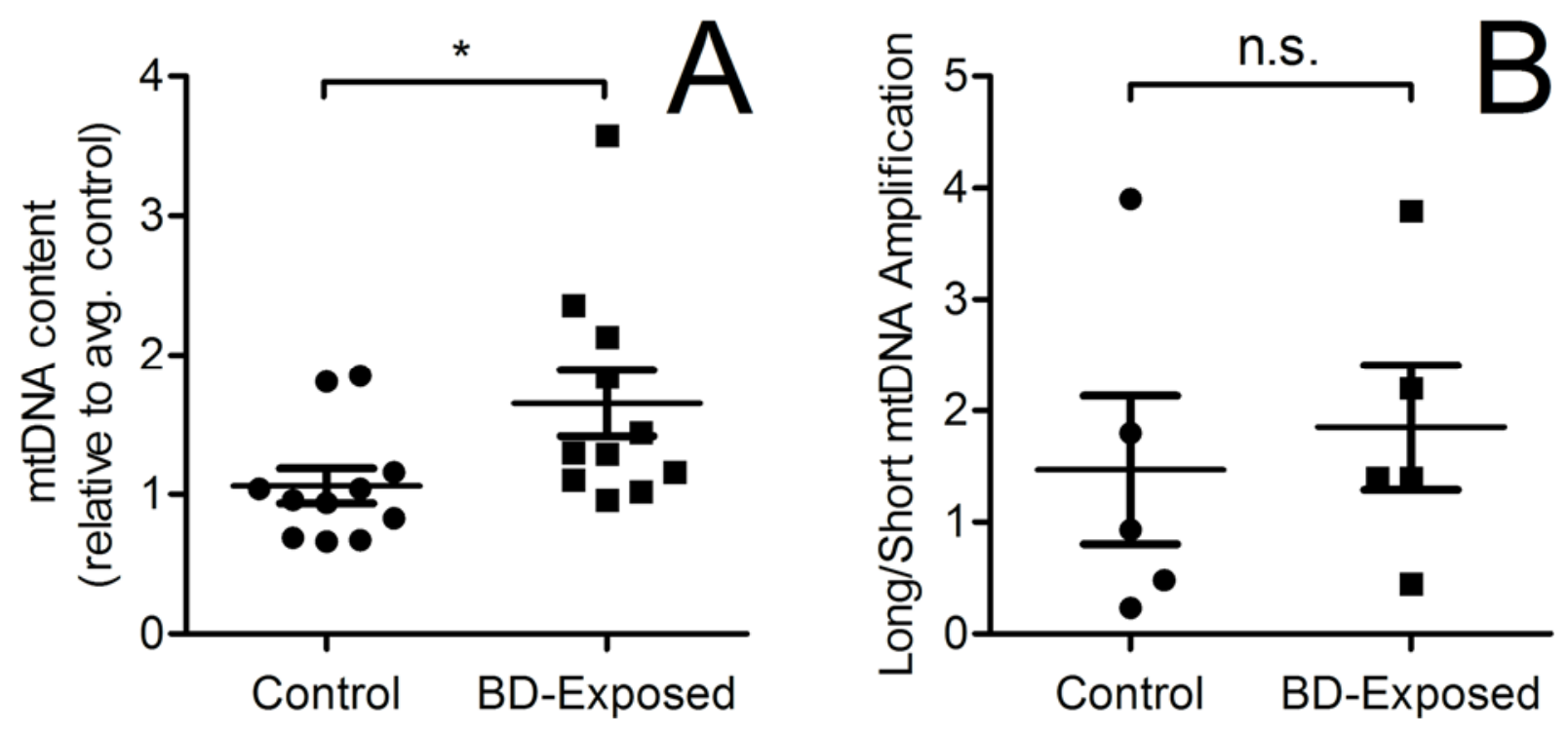
Figure 4
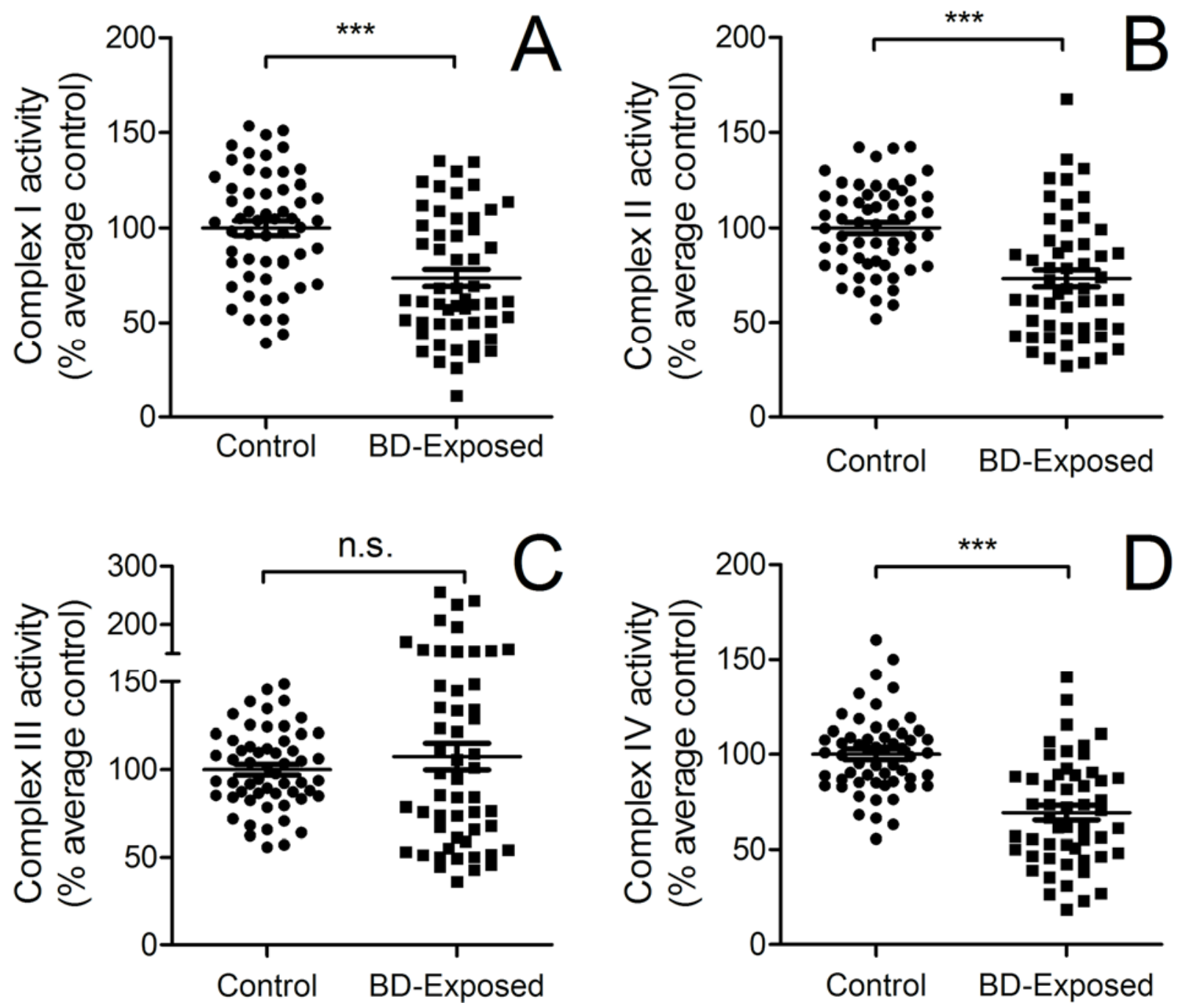
Figure 5
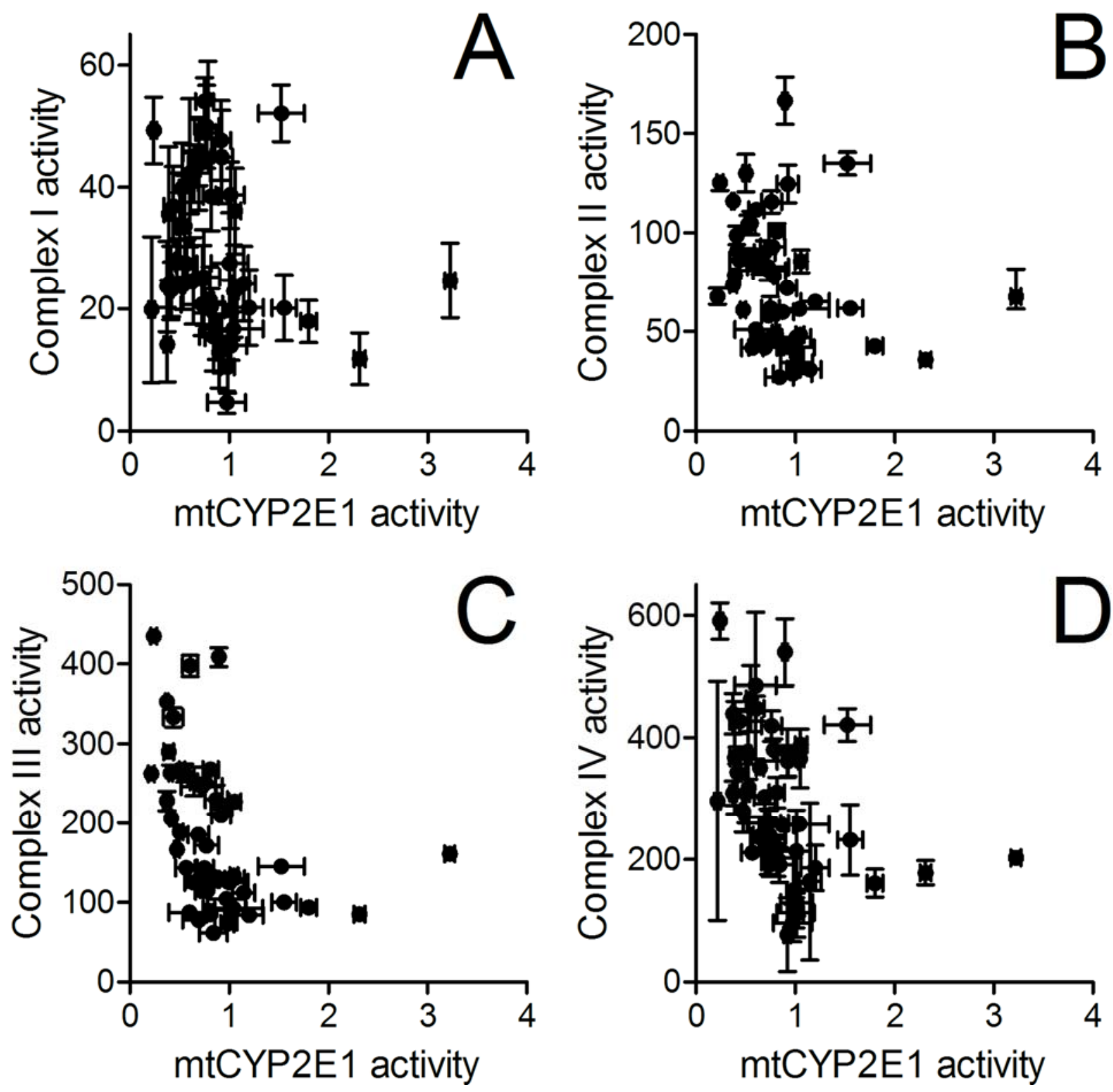
Figure 6
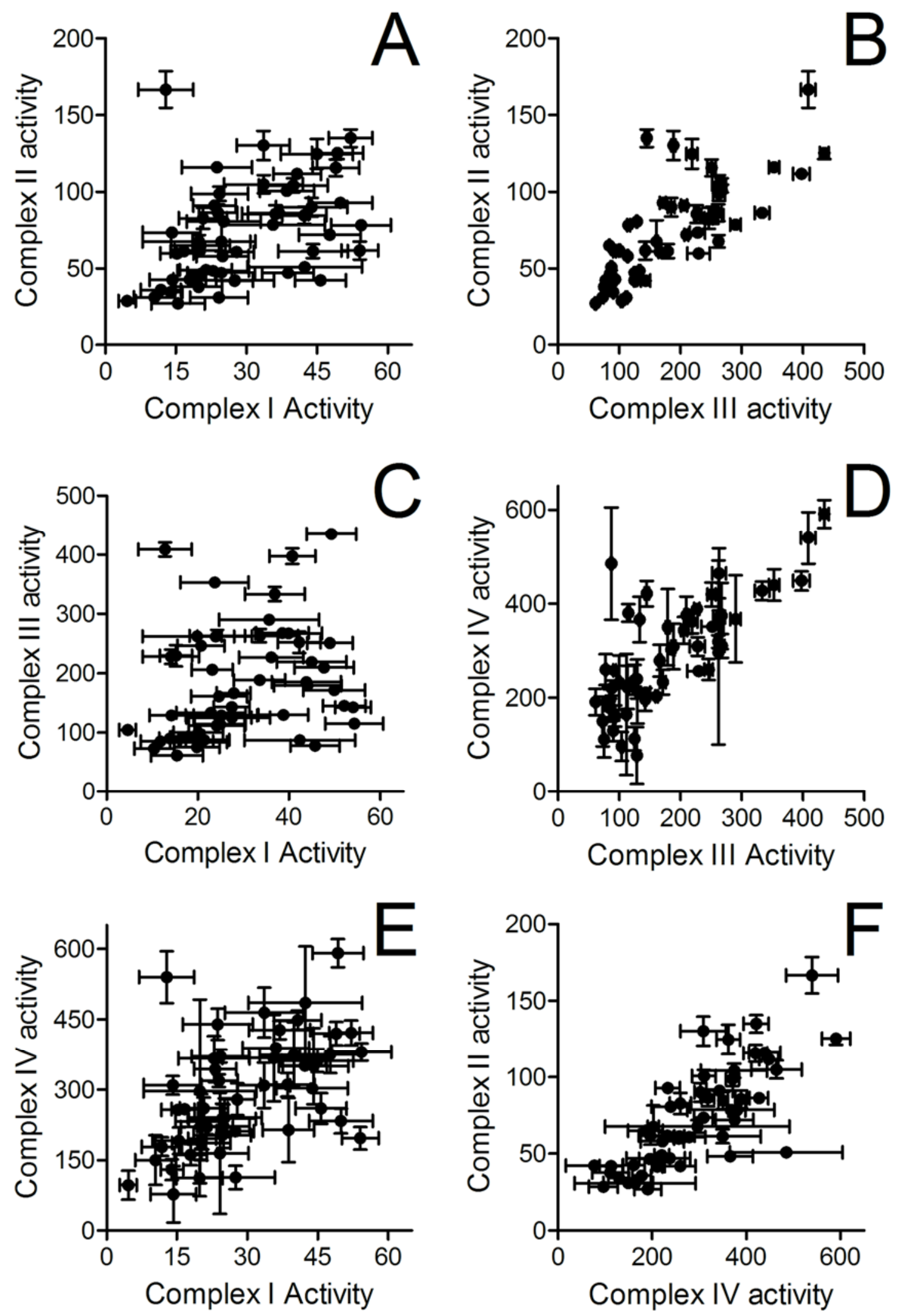